\title{
Accelerated Growth and Abnormal Glucose Tolerance in Young Female Rats Exposed to Fetal Hyperinsulinemia
}

\author{
CHUNG-JA M. CHA, NANCY L. GELARDI, AND WILLIAM OH \\ Department of Pediatrics, Brown University Program in Medicine, Women and Infants Hospital of Rhode Island, \\ Providence, Rhode Island 02905
}

\begin{abstract}
This study was designed to evaluate the relationship between fetal macrosomia and postnatal growth as well as the glucose homeostasis in young female rats. We produced fetal macrosomia by fetal insulin injection at $201 / 2$ days of gestation. The control subjects were injected with saline. The weights were recorded weekly from birth up to 12 wk. Only the female rats were studied. At 4, 6, 10, and 12 wk of age, oral glucose tolerance tests were performed. Also, at wk 6,10 , and 12, peri-renalovarian-salpingeal fat weights, the RNA, DNA, and protein contents of the abdominal muscle were determined. Onehundred seventeen control and 78 macrosomic rats were studied. The macrosomic rats showed a higher body weight (10-12\%) than the control rats from birth up to $8 \mathrm{wk}$, but at 10 and 12 wk their weights were similar. The fat weights reflected the body weights, i.e. a higher fat weight in the macrosomic rats during the period of accelerated growth (from birth up to $8 \mathrm{wk}$ ), and a similar fat weight when the body weight of the two groups were similar at 10 and 12 wk. At 4 and 6 wk of age, the plasma glucose level measured in response to the oral glucose loading were similar in both groups. However, at 10 and 12 wk of age, the macrosomic rats had significantly higher fasting plasma glucose levels and exhibited consistently higher plasma glucose levels for the 3.5 -h period of postglucose administration compared to the control rats. The plasma insulin levels rose significantly following glucose challenge. However, the values were similar in both groups at 10 and 12 wk. We conclude that the primary hyperinsulinemiainduced fetal macrosomia is associated with an increased fat deposition resulting in an increased weight gain during young adulthood. The increased fat deposition may manifest peripheral insulin resistance exhibiting the glucose intolerance at a later age. The mechanism involved in this development remains to be investigated. (Pediatr Res 21: 83-87, 1987)
\end{abstract}

\section{Abbreviations}

IDM, infants of diabetic mothers

ANOVA, analysis of variance

Macrosomia is a frequently observed complication in IDM, particularly if the medical management of diabetes during preg-

Received July 15, 1986; accepted September 10, 1986

Address for reprints William Oh, M.D.. Women and Infants Hospital, 101 Dudley Street, Providence, RI 02905.

Supported by Perinatal Emphasis Research Center Grant P50 HD11343-07 from the National Institutes of Child Health and Human Development. Bethesda. MD. nancy is inappropriate $(1,2)$. It has been speculated that the accelerated fetal growth is due to a combination of fetal hyperinsulinemia and an abundance of nutrients of growth $(3,4)$. Neonatal macrosomia, in turn, is associated with an increase risk for birth injury because of difficulty in delivering the large infant (5). Furthermore, Vohr et al. (6) and Pettitt et al. (7) have observed that IDM who are macrosomic at birth have a predisposition to obesity during adolescence. Obesity is a well-known predisposing factor for the development of adult onset diabetes; it becomes a relevant question in regard to the potential effect of obesity in the development of adult onset diabetes in these subjects. An important public health concern is the prevention of obesity in these subjects to minimize the incidence of adult onset diabetes. A relevant approach in prevention is to understand the pathophysiology in the development of obesity. This investigation is difficult to do in human subjects because of the need for long term follow-up, invasiveness in study design, and difficulty in controlling multiple variables that may influence growth. Therefore, there is a need for an animal model that simulates a nongenetically related obesity in order to study the interrelationship between fetal metabolic milieu, fetal growth, postnatal nutrition, development of obesity, and glucose homeostasis.

Catlin et al. (8) have shown that fetal hyperinsulinemia induces accelerated fetal growth and the latter is associated with persistence of accelerated growth during the first $2 \mathrm{wk}$ of life in rats. It is not certain whether this growth acceleration persists beyond this period of time or not.

The purpose of this study is to: 1) extend the study of Catlin et al. (8) to ascertain the persistence of growth acceleration in young female rats, 2) examine the changes in muscle cell composition in these experimental subjects, and 3) demonstrate the relationship between accelerated growth and abnormal glucose homeostasis.

\section{MATERIALS AND METHODS}

Catlin's modification (8) of Angervall's modified version (9) of Picon's original procedure (10) was used to produce fetal hyperinsulinemia. Time-dated pregnant Sprague-Dawley rats between 11 and 15 days of gestation (sperm positive day is considered as day 1) were purchased from Taconic Farms (Germantown, NY). The rats were housed individually in woodchip bedded plastic cages, kept in an air-conditioned room (23-25 C), with light-dark cycles of 12-h each, and allowed free access to a stock diet and water. On day 18 of gestation, $20 \%$ dextrose solution was substituted for water as the sole drinking water. This substitution of dextrose solution obviated fatal maternal hypoglycemia after fetal insulin injections (11). Five $\mathrm{mg}$ of progesterone were injected intramuscularly daily on days 19 through 21 to prolong the pregnancy to 22.5 days. On 20.5 day of gestation, laprotomy incision was made under light ether 
anesthesia. The uterus was exposed and the fetuses numbered and recorded in the laboratory log book from the left ovary proceeding caudally. Alternate fetuses were injected with either $2 \mathrm{U}(50 \mu \mathrm{l})$ of protamine zinc insulin (designated as experimental animals) under the dorsal skin or an equal volume of normal saline (designated as control animals).

On day 22.5 of gestation, the rat pups were delivered by cesarean section. Pups were washed, weighed, tagged, and transferred to foster mothers. Average pup number per nursing dam was kept between six to eight to maintain a constant postnatal nutritional intake. We found in our previous experiments that the number of pups per litter of nursing mother may significantly influence the postnatal nutrition and growth (12). Maintaining a constant number of litter size in the study groups will eliminate this factor as a confounding variable. In preliminary experimentals we also found the biological mothers, following cesarean section, cannibalized their pups. Therefore, we used foster mothers, who had natural delivery of their own pups 1-2 days before, to nurse the experimental pups. We classified pups into two groups depending on the body weight at cesarean section: 1) control group: these are saline-injected pups, 2) macrosomic group: these are insulin-injected pups whose body weights were more than 1.7 SD of the control group. The insulin-injected pups whose birth weights were less than 1.7 SD of the control groups were excluded. The sexes of the pups were identified by the end of the lst wk by examining the external genitalia. Only female subjects in both groups were included in the study. The number of subjects in each group that constituted the study population are listed in Table 1.

Pups were allowed to be nursed ad libitum and weighed daily until they were weaned. Between 3-4 wk of age, when the pups were weaned, they were housed separately, and given rat food and water ad libitum. The body weight changes were recorded weekly. At 6,10 , and $12 \mathrm{wk}$ of age rats were sacrificed for body composition study. Rats were anesthetized with ether and the abdominal muscle removed quickly, blotted, and chilled on an ice cold dish. In 49 of the 68 rats, the entire fat tissue surrounding the kidney, ovary, and Fallopian tubes were removed, blotted, and weighed. We called this peri-renal-ovarian-salpingeal fat. Muscle protein was determined by a method involving the binding of Coomasie Brilliant Blue G-250 to protein (13). Nucleic acids were extracted by a modified procedure of Fleck and Munro (14). RNA was determined by the method used by Halliburton and Thomsom (15), and DNA was estimated by the method of Dische (16).

At $4,6,10$, and 12 wk of age, 80 rats were studied for glucose tolerance using oral glucose tolerance tests as described below. Rats were fasted for $15 \mathrm{~h}$ by removing the rat food, but allowing free access to water. The oral glucose tolerance tests were done without anesthesia. Basal fasting blood samples were obtained from the rat's tail. The glucose solution, $1 \mathrm{~g} / \mathrm{ml}$, in a dose of 3 $\mathrm{g} / \mathrm{kg}$ of body weight was administered via a polyurethane catheter attached to a syringe. Blood samples were collected at time intervals of $0.5,1,2$, and $3.5 \mathrm{~h}$ after the oral glucose loading. The plasma was analyzed for glucose as soon as possible and the remaining plasma was kept frozen at $-80^{\circ} \mathrm{C}$ for insulin assay. Because of limited sample size, plasma insulin assay were not performed at 4- and 6-wk age groups. Plasma glucose was deter-

Table 1. Number of subjects in various study protocol

\begin{tabular}{lcccc}
\hline Group & $\begin{array}{c}\text { Serial } \\
\text { growth } \\
\text { assessment }\end{array}$ & $\begin{array}{c}\text { Muscle } \\
\text { composition } \\
\text { and fat wt }\end{array}$ & $\begin{array}{c}\text { Glucose } \\
\text { tolerance }\end{array}$ & Total \\
\hline Control & 32 & $40(30)^{*}$ & 45 & 117 \\
Macrosomic & 15 & $28(19)$ & 35 & 78 \\
Total =195 & & & & \\
\hline
\end{tabular}

* Number in parentheses indicated the number of rats within the muscle comparison group that were used for peri-renal-ovarian-salpingeal fat measurements. mined using the glucose-oxidase method by means of Glucose Analyzer YSI 23A (Yellow Springs Inst. Co., Yellow Springs, $\mathrm{OH})$. Plasma insulin levels were determined by radioimmunoassay method using a double antibody polyethylene glycol separation procedure (Serono Diagnostics, Braintree, MA).

Statistical analysis. Statistical significance for changes in weight with age and plasma glucose and insulin following glucose administration was analyzed by ANOVA and the significant main effect was identified by post hoc $t$ tests. For intergroup differences in muscle composition and fat weight as well as oral glucose tolerance values, unpaired $t$ tests were used with Fisher's exact test correction where appropriate.

\section{RESULTS}

Figure 1 shows the significant increment weight of the study rats at weekly intervals during the first $12 \mathrm{wk}$. The macrosomic female rats were consistently heavier during the first $8 \mathrm{wk}$, averaging between $10-12 \%$ higher in their weights than the saline injected female control. At 9-12 wk of age, the differences were no longer observed. Figure 2 shows the weight gain velocity calculated by the formula of Pomerance (17) at weekly intervals; it shows that the changes in weight velocity in the first $12 \mathrm{wk}$ did not differ between the two groups.

Table 2 shows the cell composition of the abdominal muscle of control and macrosomic female rats at different age periods. At birth, the RNA content is higher in macrosomic rats, while at $6 \mathrm{wk}$, the DNA content was higher. At 10 and $12 \mathrm{wk}$, both RNA and DNA contents were similar in the two groups. The RNA/DNA ratios were similar between the two groups throughout the $12 \mathrm{wk}$. The protein content was higher in the macrosomic group at $6 \mathrm{wk}$, but less at $10 \mathrm{wk}$ of age.

Table 3 shows the peri-renal-ovarian-salpingeal fat weights in the two groups. At $6 \mathrm{wk}$, the macrosomic rats have significantly higher fat weights than control, both as absolute weights and as relative weight as expressed per unit body weight. At 10 and 12 wk of age the differences were no longer observed.

Table 4 shows the results of the oral glucose tolerance test at $4,6,10$, and 12 wk of age. Except for the $1 / 2$ h result at 6 wk of age, in which the plasma glucose is significantly higher in the macrosomic group, the oral glucose tolerance results at 4 and 6

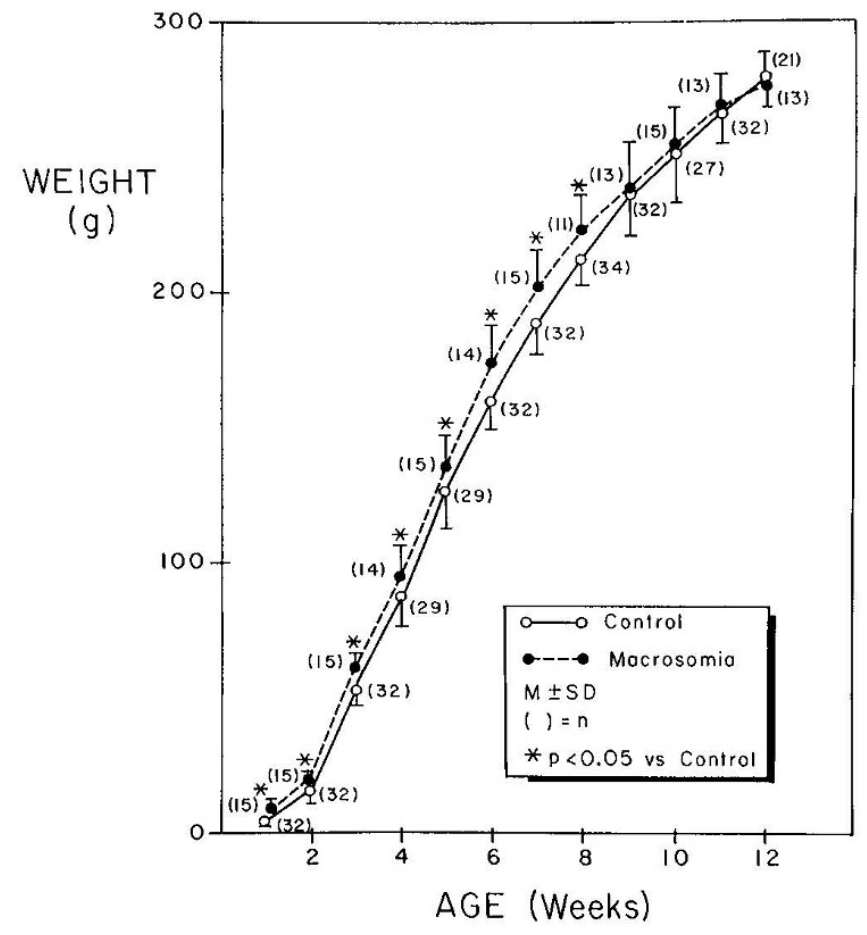

Fig. 1. Changes in body weight in control and macrosomic female rats during the first $12 \mathrm{wk}$. 
wk of age were similar between the two groups. At 10 and $12 \mathrm{wk}$ of age, the plasma glucose values were significantly higher both at fasting and at $1 / 2,2$, and $3.5 \mathrm{~h}$ following the oral glucose administration in the macrosomic rats.

Because of the size of the animals, the plasma insulin determinations were not performed at 4 and $6 \mathrm{wk}$ of age. At $10 \mathrm{wk}$ of age there is a significant increase in the insulin values in both the control and macrosomic group, within the group, at 0.51 , and $2 \mathrm{~h}$ after glucose adminstration, as shown in Table 5 . However, at $12 \mathrm{wk}$ of age, only the macrosomic group showed a significant increase in the insulin level at $0.5,1$, and $2 \mathrm{~h}$ after glucose administration while the insulin increase in the control group was not significant statistically. Insulin values were also compared between the groups, i.e. control and macrosomic, for the hours we studied following glucose administration at 10 and $12 \mathrm{wk}$ of age. The insulin values in the macrosomic group were consistently higher than the control group following the oral
Table 3. Peri-renal-ovarian-salpingeal fat $*$

\begin{tabular}{llccc}
\hline & & \multicolumn{3}{c}{ Age (wk) } \\
\cline { 3 - 5 } & & 6 & 10 & 12 \\
\hline Fat & Control & $2.1 \pm 0.6$ & $7.1 \pm 1.1$ & $8.2 \pm 2.4$ \\
wt (g) & Macrosomic & $3.3 \pm 0.4$ & $7.8 \pm 1.9$ & $9.2 \pm 3.0$ \\
& $p$ & $<0.01$ & NS & NS \\
& & & & \\
Fat wt & Control & $1.3 \pm 0.4$ & $3.1 \pm 0.4$ & $3.1 \pm 0.8$ \\
Body wt & Macrosomic & $1.9 \pm 0.2$ & $3.2 \pm 0.8$ & $3.2 \pm 0.8$ \\
& & & & \\
& $p$ & $<0.01$ & NS & NS \\
$n$ & & & & \\
& Control & 7 & 6 & 17 \\
& Macrosomic & 5 & 5 & 9 \\
\hline
\end{tabular}

$*$ Mean \pm SD.

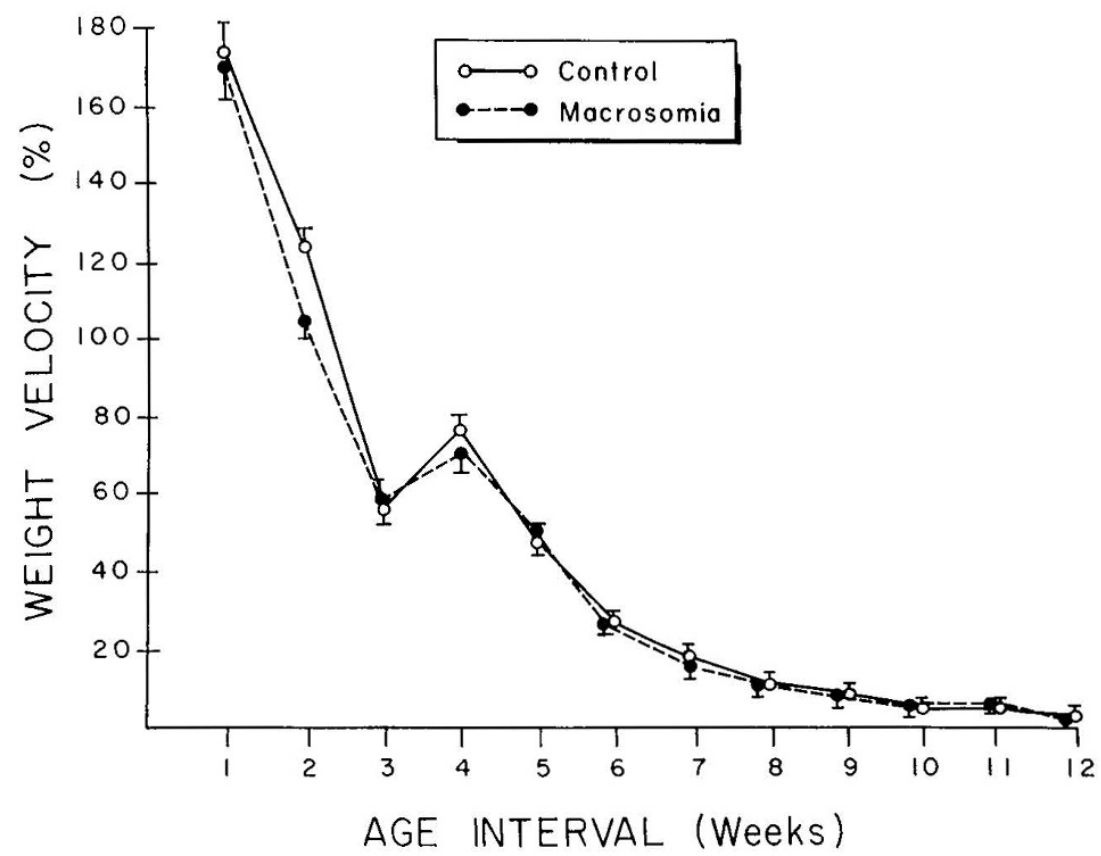

Fig. 2. Weight velocity change in control and macrosomic female rats during the first $12 \mathrm{wk}$.

Table 2. Cell composition of abdominal muscle

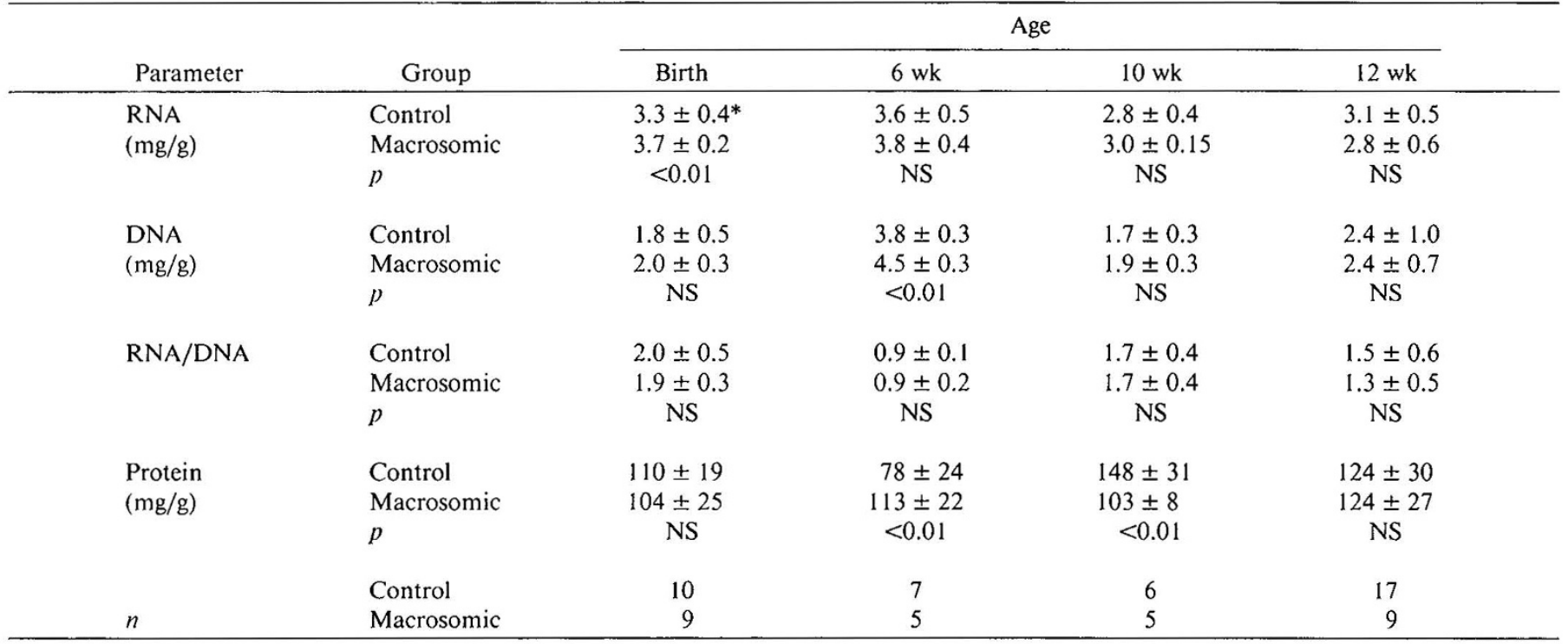

* Mean $\pm \mathrm{SD}$. 
glucose challenge, although the statistical significance was observed only at $2 \mathrm{~h}$ in the 12 -wk-old rats.

\section{DISCUSSION}

The current study extended the observations of Catlin et al. (8) in regard to the persistence of macrosomia in female rats during the first $8 \mathrm{wk}$. The first $8 \mathrm{wk}$ of rat's life is equivalent to young adulthood in humans. Therefore, the current study doc-

Table 4. Plasma glucose levels in young female rats following oral glucose tolerance test*

\begin{tabular}{|c|c|c|c|c|}
\hline \multirow[b]{2}{*}{$\operatorname{Agc}(w k)$} & \multirow{2}{*}{$\begin{array}{l}\text { H following } \\
\text { glucose } \\
\text { load }\end{array}$} & \multicolumn{2}{|c|}{ Glucose (mg/dl) } & \multirow[b]{2}{*}{$p$} \\
\hline & & Control & Macrosomic & \\
\hline \multirow[t]{6}{*}{4} & $n$ & 7 & 11 & \\
\hline & Fasting & $49 \pm 15$ & $69 \pm 28$ & NS \\
\hline & 0.5 & $159 \pm 33$ & $163 \pm 32$ & NS \\
\hline & 1 & $143 \pm 10$ & $152 \pm 24$ & NS \\
\hline & 2 & $118 \pm 12$ & $107 \pm 24$ & NS \\
\hline & 3.5 & $95 \pm 22$ & $98 \pm 16$ & NS \\
\hline \multirow[t]{6}{*}{6} & $n$ & 7 & 5 & \\
\hline & Fasting & $63 \pm 14$ & $55 \pm 9$ & NS \\
\hline & 0.5 & $142 \pm 18$ & $167 \pm 20$ & $<0.05$ \\
\hline & 1 & $155 \pm 9$ & $153 \pm 16$ & NS \\
\hline & 2 & $129 \pm 16$ & $114 \pm 6$ & NS \\
\hline & 3.5 & $116 \pm 12$ & $103 \pm 12$ & NS \\
\hline \multirow[t]{6}{*}{10} & $n$ & 16 & 12 & \\
\hline & Fasting & $84 \pm 8$ & $96 \pm 15$ & $<0.005$ \\
\hline & 0.5 & $171 \pm 39$ & $196 \pm 30$ & $<0.025$ \\
\hline & 1 & $162 \pm 30$ & $176 \pm 15$ & NS \\
\hline & 2 & $113 \pm 26$ & $130 \pm 10$ & $<0.01$ \\
\hline & 3.5 & $95 \pm 18$ & $109 \pm 14$ & $<0.01$ \\
\hline \multirow[t]{6}{*}{12} & $n$ & 15 & 7 & \\
\hline & Fasting & $79 \pm 20$ & $101 \pm 19$ & $<0.01$ \\
\hline & 0.5 & $165 \pm 48$ & $193 \pm 29$ & NS \\
\hline & 1 & $169 \pm 14$ & $198 \pm 40$ & $<0.01$ \\
\hline & 2 & $122 \pm 28$ & $161 \pm 40$ & $<0.005$ \\
\hline & 3.5 & $103 \pm 34$ & $142 \pm 28$ & $<0.01$ \\
\hline
\end{tabular}

$*$ Mean $\pm \mathrm{SD}$. umenting the persistence of accelerated growth in rats is consistent with human observations $(6,7)$ that show a high incidence of obesity during prepuberty and adolescent periods in those infants of the diabetic mother who were macrosomic at birth. In the human studies, multiple variables are likely to influence the growth pattern, so that a direct implication of birth status and the growth pattern in later childhood cannot be established. In the rat studies, we have controlled the nutritional status postnatally, and socioeconomic or demographic factors are not confounding variables; therefore, it is likely that the observation of accelerated growth during later childhood is a function of the birth size.

We analyzed the nucleic acid content of the muscle as a means of assessing the cell composition with reference to the size and the number during growth. The choice of muscle as tissue for assessment of cell growth with reference to RNA and DNA as reflection of hypertrophy and hyperplasia respectively is based on two reasons: 1) muscle is the major component of body mass and 2) because of the good correlations of RNA and DNA to cell proliferation and growth (18). While there are some changes in cell size and cell number, the RNA/DNA ratio is consistently similar between the two groups throughout the study period. While at some point, there is an increase in cell multiplication, this is compensated by a reduction in cell size and vice versa. Thus, the accelerated growth in female macrosomic rats during the first $8 \mathrm{wk}$ is most likely to be a result of the increase in cell proliferation and hypertrophy in the major organ, such as muscle. The similarity in the growth velocity in the two groups is also consistent with the observation in the cell composition in that the accelerated growth is generally on the basis of the initial birth size rather than a spurt in growth in one group (the macrosomic group) over the other (the control). The lower protein content in the macrosomic group at $10 \mathrm{wk}$ is of interest, but we cannot offer a logical explanation for it.

The higher fat weights in the macrosomic rat at $6 \mathrm{wk}$ is of interest in that the increase in fat content may well account for the higher growth rate in this group. The lack of difference in the fat weight at 10 and $12 \mathrm{wk}$ is also consistent with the fact that at this age period the body weight between the two groups were similar. This observation is particularly important with reference to our observations of glucose intolerance in the experimental group in that the high fat content may account for the increased metabolic activity in these tissues, which may lead to peripheral insulin resistance as has been observed in adult onset diabetes (19). The increased insulin resistance in the peripheral

Table 5. Plasma insulin in female rats following oral glucose tolerance test*

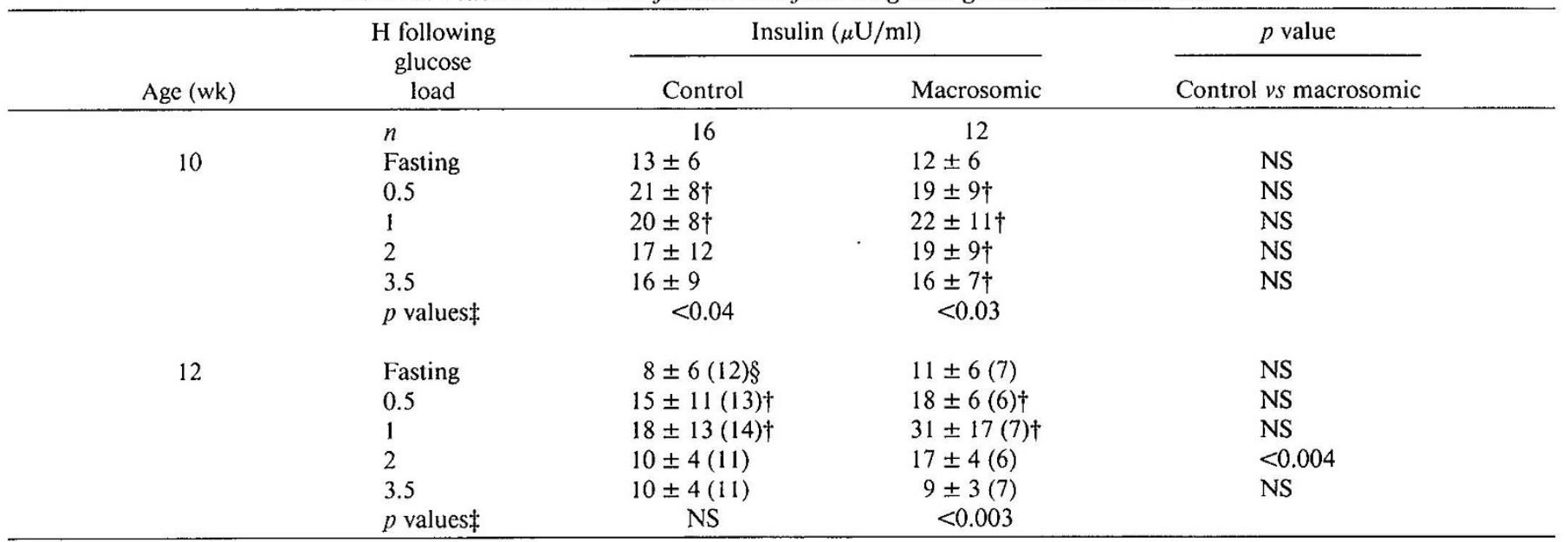

* Mean \pm SD.

† Significant at $p$ value $<0.05$ compared with the fasting values by post hoc $t$ test.

$\$$ ANOVA comparing changes of plasma insulin following oral glucose administration.

$\S n$. 
tissue is evidenced by the presence of higher plasma glucose value in the face of a significant rise in plasma insulin concentration. The precise mechanism and ontogeny of the peripheral insulin resistance in the macrosomic subject is not clear and remains to be investigated.

It is also of interest that the glucose intolerance develops only at 10 and $12 \mathrm{wk}$ of age, at the point when there is no longer an observed difference in the body weight as well as fat pad weights. The mechanism for this observation is unclear. One can speculate that the factor(s) responsible for the abnormal glucose homeostasis observed in macrosomic rats at this age was in progress during the period of accelerated growth and became overtly apparent at a later age. The precise mechanism remains to be elucidated.

\section{REFERENCES}

1. Oh W 1979 Neonatal care and long term outcome of infants of diabetic mothers. In: Merkatz IR. Adam PAJ (eds) The Diabetic Pregnancy: A Perinatal Perspective. Grune \& Stratton, New York, pp 195-205

2. Widness JA. Schwartz HC, Thompson D, King KC, Kahn CB, Oh W, Schwartz $\mathrm{R} 1978$ Glycohemoglobin $\left(\mathrm{HbA}_{\mathrm{Ic}}\right)$ : a predictor of birth weight in infants of diabetic mothers. J Pediatr 92:8-12

3. Pedersen J 1977 Hyperglycemic-hyperinsulinism theory and birth weight. In: The Pregnant Diabetic and Her Newborn, 2nd ed. Williams \& Wilkins. Baltimore, pp $211-220$

4. Freinkel N. Metzger BE 1979 Pregnancy as a tissue culture experience: the critical implications of maternal metabolism for fetal development. In: Pregnancy Metabolism. Diabetes and The Fetus. CIBA Foundation Symposium 63. Exccrpta Medica, Amsterdam

5. Acker DB. Sachs BP. Friedman EA 1985 Risk factors for shoulder dystocia. Obstet Gynecol 66:762-768
6. Vohr BR, Lipsitt LP. Oh W 1980 Somatic growth of children of diabetic mothers with reference to birth size. J Pediatr 97:196-199

7. Pettit DJ, Baird HR, Aleck KA, Bennett PH, Knowler WC 1983 Excessive obesity in offspring of Pima Indian Women with diabetes during pregnancy. N Engl J Med 308:242-245

8. Catlin EA, Cha C-JM, Oh W 1985 Postnatal growth and fatty acid synthesis in insulin-induced macrosomic rat pups. Metabolism 34:1110-1114

9. Angervall L, Karlsson K, Martinsson A 1981 Effects on rat fetuses of intrauterine injection of insulin. Diabetologia 20:558-562

10. Picone $L 1967$ Effect of insulin on growth and biochemical composition of the rat fetus. Endocrinology 81:1419-1421

11. Vileisis RA, Oh W 1983 Enhanced fatty acid synthesis in hyperinsulinemic rat fetuses. J Nutr 113:246-252

12. Cha C-JM, Oh W 1986 Growth and fatty acid metabolism in experimental intrauterine growth retardation: effect of postnatal nutrition. J Nutr 116:1080-1087

13. Bradford MM $1976 \mathrm{~A}$ rapid and sensitive method for the quantification of microgram quantities of protein utilizing the principle of protein-dye binding. Anal Biochem 72:248-254

14. Fleck A, Munro HN 1962 The precision of ultraviolet absorption measurements in the Schmidt-Thannhauser procedure for nucleic acid estimation. Biochim Biophys Acta 55:571-583

15. Halliburton IW, Thomson RY 1965 Chemical aspects of compensatory renal hypertrophy. Cancer Res 25:1882-1887

16. Dische A 1955 Color reactions of nucleic acid components. In: Chargaff $\mathrm{E}$ Davison JN (eds) Nucleic Acids, Vol 1. Academic Press, New York, pp 285305

17. Pomerance HH 1979 A longitudinal study: incremental growth and velocity curves. In: Growth Standards in Children. Harper \& Row, New York, pp 107-128

18. Cheek DB, Beatly CH, Scott RE, Bocek RM 1975 Muscle development in the fetus. In: Cheek DB (ed) Fetal and Postnatal Cellulus Growth. John Wiley and Sons, New York, pp 243-272

19. Felig P, Owen OE, Morgan AP, Cahill GF 1968 Utilization of metabolic fuels in obese subjects. Am J Clin Nutr 21:1429-1433 